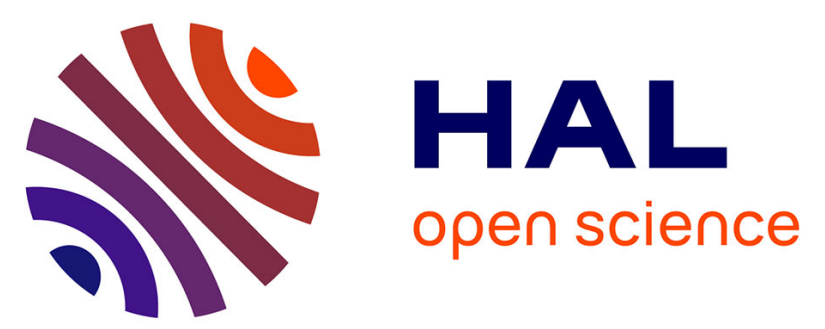

\title{
Comments on the article "Uncertainty and bias in electronic tide-gauge records: Evidence from collocated sensors" by Stella Pytharouli, Spyros Chaikalis, Stathis C. Stiros in Measurement (Volume 125, September 2018) T. Aarup, Guy Woppelmann, P.L. Woodworth, F. Hernandez, B. Vanhoorne, T. Schöne, P.R. Thompson
}

\section{To cite this version:}

T. Aarup, Guy Woppelmann, P.L. Woodworth, F. Hernandez, B. Vanhoorne, et al.. Comments on the article "Uncertainty and bias in electronic tide-gauge records: Evidence from collocated sensors" by Stella Pytharouli, Spyros Chaikalis, Stathis C. Stiros in Measurement (Volume 125, September 2018). Measurement - Journal of the International Measurement Confederation (IMEKO), 2019, 135, pp.613-616. 10.1016/j.measurement.2018.12.007 . hal-01956455

\section{HAL Id: hal-01956455 \\ https://hal.science/hal-01956455}

Submitted on 3 Jan 2019

HAL is a multi-disciplinary open access archive for the deposit and dissemination of scientific research documents, whether they are published or not. The documents may come from teaching and research institutions in France or abroad, or from public or private research centers.
L'archive ouverte pluridisciplinaire HAL, est destinée au dépôt et à la diffusion de documents scientifiques de niveau recherche, publiés ou non, émanant des établissements d'enseignement et de recherche français ou étrangers, des laboratoires publics ou privés. 
Comments on the article "Uncertainty and bias in electronic tide-gauge records: evidence from collocated sensors" by Stella Pytharouli, Spyros Chaikalis, Stathis C. Stiros in Measurement (Volume 125, September 2018)

4

T. Aarup ${ }^{1}$, G. Wöppelmann ${ }^{2}$, P.L. Woodworth ${ }^{3}$, F. Hernandez ${ }^{4}$, B. Vanhoorne ${ }^{4}$, T. Schöne ${ }^{5}$ and P.R. Thompson $^{6}$

${ }^{1}$ IOC/UNESCO, 7 place Fontenoy, 75007 Paris, France

$8{ }^{2}$ LIENSS, ULR - CNRS, 2 rue Olympe de Gouges, 17000 La Rochelle, France

$9{ }^{3}$ NOC, 6 Brownlow Street, Liverpool L3 5DA, United Kingdom

$10{ }^{4}$ VLIZ, Wandelaarkaai 7, 8400 Oostende, Belgium

$11{ }^{5}$ GFZ German Research Centre for Geosciences, 14473 Potsdam, Germany

$12{ }^{6}$ University of Hawai'i Sea Level Center, 1000 Pope Road, MSB 317, Honolulu, HI 96822, USA

13

Corresponding author: Guy Wöppelmann

E-mail : guy.woppelmann@univ-Ir.fr

Declarations of interest: none. 
Abstract

24 This note comments on the article published in Measurement by Stella Pytharouli, Spyros Chaikalis and Stathis C. Stiros (Volume 125, September 2018) entitled "Uncertainty and bias in electronic tide-gauge records: evidence from collocated sensors". That paper comprises a set of comparisons between sea level data obtained by two or three collocated sensors at 10 sites around the world, using statistical methods akin to the buddy-checking methods that are often used by tide gauge operators. Their paper contains a number of incorrect statements. In addition, its comparison of tide gauge data at the 10 sites, which comprises most of the paper, is flawed in several respects.

32

Keywords: Sea level database; Tide gauge records; Tide gauge benchmarks; Openly accessible data; GLOSS programme

We refer to a recent article "Uncertainty and bias in electronic tide-gauge records: evidence from collocated sensors" published in Measurement by Stella Pytharouli, Spyros Chaikalis and Stathis C. Stiros. This comment aims at correcting some incorrect statements in that paper. In addition, we hope to clarify some important aspects to do with the source of the data used in their study, so as to enable any reader to better understand the findings presented.

42

The authors looked at sea level data obtained by two or three collocated sensors at 10 sites around the world, and made comparisons between the different sensors using statistical 
methods akin to the buddy-checking methods that are often used by tide gauge operators (IOC 2016).

(1) They mention that their comparisons were limited by the number of sites with collocated sensors. They state (page 496) that "Currently, the percentage of sites with collocated sensors is of the order of a few percent of the total sites covered with tide-gauges."

Most tide gauge sites from which data are provided to the Intergovernmental Oceanographic Commission (IOC) Global Sea Level Observing System (GLOSS), the Permanent Service for Mean Sea Level (PSMSL), and the University of Hawai'i Sea Level Center (UHSLC) have multiple sensors. For example, most stations in the UK National Network (with which, given the address, one would have assumed the lead author to be familiar) contain dual bubbler systems. Data from both primary and secondary channels can be downloaded readily from the British Oceanographic Data Centre (BODC, https://www.bodc.ac.uk).

Other examples include the modern US (NOAA) network and the international network maintained by the UHSLC. The former has been based on acoustic sensors supplemented by pressure sensors, although that network is now transitioning to radar sensors (Park et al. 2014). The latter is primarily based on radar sensors (often two radars at each site) supplemented by pressure sensors when possible. Detailed descriptions of sea level recording in many other countries can be obtained from the national reports to regular 
meetings of the GLOSS programme (http://www.gloss-sealevel.org/) and those reports show that most countries employ two or more sensors at each site.

All of the data from duplicate or multiple sensors will be available for inspection by the owners of the sites and the local technical specialists. However, it is not necessarily the case that data from all sensors are passed to the IOC Sea Level Station Monitoring Facility (SLSMF) at the Flanders Marine Institute (http://www.ioc-sealevelmonitoring.org/), which is where Pytharouli et al. obtained their data. For example, in the case of the UK, data from only the so-called primary bubbler channel are provided to the SLSMF.

(2) Section 2.1 states that the data used in this paper were obtained from the IOC SLSMF.

80

The IOC SLSMF was established to provide near-real time displays of data from those tide gauges around the world which are part of GLOSS or the several regional IOC tsunami networks (IOC 2012). The facility was provided primarily for the operational benefit of tide gauge owners who do not have their own display systems so that faults could be identified and fixed as soon as possible.

86

87 All data are displayed as received, archived and are accessible to interested users. However, the web site makes clear that the data has not undergone any quality control, and there is a clear disclaimer to that effect. The data providers for each station are mentioned in order to

90 facilitate contact in case of a user's concerns or requests (e.g., if data are required for commercial purposes). 
93 The data from the SLSMF have occasionally been used in scientific research. However, such

94 research has usually been made by people who are aware of the difficulties of dealing with such data and who have been able to make additional quality control. Pytharouli et al. state correctly that the "policy of IOC is to check data in time due and automatically discard or repair sections of time series, so that final records are free of errors and of significant inconsistencies". For operational or research applications, users are directed by the SLSMF to dedicated IOC/GLOSS data centres which differ in the type of data quality control applied and the delay in making data available (IOC 2012).

(3) Section 2.1 rightly mentions the need for access to metadata as well as to tide gauge data itself.

All tide gauge stations experience problems in their supply of data from time to time. Some stations are remote and will have had power outages, communication problems etc. as well as technical faults in the gauge hardware itself. Occasionally, it will have been necessary to replace the sensors. Over a period of a decade or more (this paper seems to consider data from 2007 onwards) it is inevitable that there will have been gaps in the recording or data which appears anomalous in some way.

112 When inspecting time series of real-time tide gauge data from the SLSMF (or a local display),

113 the only people who are in a position to understand anything that looks anomalous are the owners and operators of the equipment who will have access to installation reports and 
maintenance logs. Such detailed information is not available to a random user of the SLSMF web site.

118 For example, Figure 4 of the paper shows flat values near low tide for pressure sensor PRS1 119 at Aden. The installation report of the Aden station shows that PRS1 was installed as a 'half120 tide sensor' (IOC 2006) for which the observed bottoming-out at low tide was in fact 121 intentional. (PRS2 was installed much deeper than PRS1 and may also occasionally bottomout during very low tidal levels.) This is something that cannot be appreciated without some knowledge of the hardware and the station layout. A thoughtless downloading of data from all channels, and subjecting them to a statistical comparison, is pointless. The radar data from this station have proved to be very reliable (e.g. Woodworth et al. 2009). (We can further point out that the location of Aden shown in Figure 2 is incorrect.)

Section 3.2.2 refers to zero values for some or all sensors at certain sites. These can sometimes arise from local hardware malfunction but are as likely to occur from transmission errors between the station, the satellite (e.g. Meteosat), the Global Telecommunications System (GTS) and the SLSMF. Meteosat and other meteorological satellites are not $100 \%$ reliable for data transmission, with occasional bit-error corruptions and short data gaps which meteorological data users can usually tolerate. Nevertheless,

134 these satellites are made available freely to tide gauge owners in GLOSS, which explains why they have been adopted as one of the main data transmission methods for the global network. In practice, zero values can be spotted instantly and rejected from any record, with small gaps interpolated. We do not see why the authors felt the need to discuss such a trivial issue. 
140 Another example we can mention is to do with the Alexandria pressure sensors in Figure 6.

141 Alexandria was installed as part of modernisation of the African sea level network

142 (Woodworth et al. 2007) for which there were many problems with pressure sensors,

143 explaining the time series shown in this figure. Sensors were replaced from time to time,

144 hence the jumps in datum. Bad data are never removed from the SLSMF archive in case they

145 are needed again in the future, and neither are they flagged as bad, so there is always a

146 danger that they can be spotted and remarked on by authors such as the present ones who

147 are not in a position to know all the historical details. At this station the radar sensor

148 provided good data for many years (2009-2016) with monthly mean sea level values

149 included in the PSMSL data set.

150

151 A final example is the "sudden step" in the difference between radar and pressure sensors

152 from Kaumalapau, Hawai'i shown in Figure 7. The discussion of this step is rightly attributed

153 to station maintenance, but it is a naïve and misleading perspective without noting that this

154 offset is not carried forward into the quality-controlled sea level datasets provided by GLOSS

155 data centres. When a radar (or any other) sensor is serviced or replaced, it must be

156 unmounted and then remounted. Station technicians perform an engineering-grade survey

157 to find the offset of the reinstalled sensor relative to the station benchmarks. This offset is

158 then applied to the observed levels prior to distributing the data for oceanographic and 159 geodetic applications. As discussed elsewhere in this response, data from the SLSMF is for

160 real-time monitoring purposes and not appropriate for other applications. Thus, the offset 161 should not be classified as an "error" as the authors present. Rather, the offset reflects 162 water level measurements before they have been converted to sea level. By definition, 'sea 
level' is water level relative to land, or more specifically, relative to geodetic benchmarks.

Variability in SLSMF data is not guaranteed to represent sea level in this strict sense due to an inability to apply levelling offsets in real time.

Section 2.1 implies that the authors made "inquiries to tide-gauge or data basis curators", from which they might have learned more about the histories of recording at their 10 sites. That would indeed have been sensible. However, there is no record of them having made enquiries for information from IOC, SLSMF, National Oceanography Centre (NOC, which provided the Alexandria gauge), UHSLC (which provided the Hawai'i and Tern gauges), GFZ Potsdam (which provided the Aden gauge) or from any of the other station contacts given on the SLSMF web site.

(4) Different sensors for different purposes.

This leads to a further aspect of sea level recording that appears to have been ignored in the paper, which is that different sensors are installed for different purposes. The paper seems to treat all channels as equally worthy of statistical comparison.

180

The GLOSS Implementation Plan (IOC 2012) and IOC Manuals (IOC 2006; 2016) make it clear that new stations must have multiple sensors (as mentioned above, most of them already have multiple sensors). For example, radar gauges have been shown to be capable of

184 providing time series with little or no instrumental drift, unlike pressure sensors which do tend to drift. However, both are desirable at a site, given that pressure sensors can be sampled at high frequency, and so be useful for detecting processes such as seiches and 
tsunamis (and even waves if sampled at $1 \mathrm{~Hz}$ or similar). There is little point, therefore, in deriving statistical conclusions as in this paper from sensors that were installed for different purposes.

We can furthermore point out that channels of data into the SLSMF could be occasionally from experimental setups and therefore provide information that is completely meaningless to anyone else.

(5) Their abstract states "Pressure gauges were found significantly more sensitive to noise than radar-type sensors, and with higher chances of long-term transient bias".

The finding of a 'long-term transient bias' with pressure sensors is something that has been known for years (Woodworth and Smith 2003; Martin Míguez et al. 2012), and which is now discussed at length in manuals and textbooks (IOC 2006; Pugh and Woodworth 2014). In brief, pressure tide gauges are based on the principle of measuring sub-surface pressure, which is converted to height based on knowledge of the water density and local acceleration due to gravity. However, all pressure gauges are sensitive to temperature effects and are prone to instrumental ageing. Some sensors have an in-built temperature sensor to allow temperature compensation. However, large instrumental drifts have been reported in excess of $1 \mathrm{~mm} /$ year, even when using the best possible (and most costly) sensors (Martin Míguez et al. 2012). This is clearly a major concern for long-term sea level studies. (There is an additional source of datum error if pressure sensors are taken out of the water for annual maintenance and replaced at a slightly different height, see IOC 2006).

210 Pressure gauge designs exist which attempt to circumvent these problems (e.g., see 
discussion of 'B gauges' in IOC 2006). However, they can be expensive and have not been

212 adopted by most groups. As for different noise levels, one should note that measurements

213 with the same nominal sampling period (e.g. one or several minutes) are not necessarily

214 equivalent, those by pressure sensors sometimes being spot (instantaneous) measurements

215 while radar values will be averages over manufacturer-defined periods.

216

217 Why then are pressure sensors still so widely used in coastal tide gauge stations? The reason

218 is that they are particularly well suited for installation and operation in environmentally

219 hostile areas at sites with minimal infrastructure and harsh weather conditions, where the exposed structures may be subject to extreme winds and waves. Hence, they are more likely to resist and record a tsunami wave or a storm surge (identification of which does not require rigorous datum stability). Consequently, pressure gauges are important components of multi-application sea level networks such as the GLOSS core network of sea level stations, in which they complement the primary tide gauge (typically a radar sensor nowadays). We suggest that the authors read IOC (2016) for more information.

(6) The abstract further says that on average, over the 1-4 year timespan of data considered, "only 9\% of the sensors analysed were found to satisfy the 1-cm accuracy criterion" imposed by the GLOSS programme (IOC 2012).

This finding is consistent with our comments above on the way that the authors selected their data for analysis, especially since their study considered multi-year periods of operation. It is interesting that, of the ten stations with co-located sensors analysed in their paper, only Punta Cana, Dominican Republic had two co-located sensors which were both 
radar gauges. The radar technique has progressively replaced the previous tide gauge technologies over the past decade (e.g., Martin Míguez et al 2008; Park et al. 2014), even though additional research is required concerning their longer-term suitability at some locations (IOC 2016). It is thus comforting to read that a $1.8 \mathrm{~cm}$ rms (root mean square) difference between sensors was found at Punta Cana, and no substantial bias reported over a 518-days long recording time span.

(7) Section 4.9 states that "Errors usually found in raw tidal data are removed and not displayed in data bases. Such modification tends to shadow important metrological information. On the contrary, raw and corrected data sets should be fully shown, as is the case in disciplines, for example in data bases used in Climatology"

This is a misleading statement. When raw data are passed for further quality control to the other centres connected with the GLOSS programme (IOC 2012), they are processed to modern data management standards, with all data flagged and capable of recovery and not simply deleted. As the lead author is based in the UK, we suggest that she discusses with BODC how they process and archive sea level data.

(8) Section 2.2.1 states that to provide records with a common datum one needs 19 years of data.

This is a tangential point but is worth clarifying. The text is alluding to the traditional requirement for 18.6 years of data for the definition of hydrographic datums such as Lowest Astronomical Tide (a requirement that in practice is almost never met). However, in the 
context of a common datum discussed here, there is no data requirement at all. Provision of a common datum is a simple technical issue.

261

In conclusion, we believe that this paper is misleading in several respects and that the 263 statistical analyses undertaken have little value. In our opinion, if the authors intend to 264 continue investigating tide gauge data, we encourage them to engage properly with IOC, SLSMF, NOC or UHSLC and to understand properly the data that they are dealing with. Blind 266 data mining studies such as this are of little value. At least we can agree with the paper ending on a positive note, recognising that it is becoming increasingly common to have multiple sensors at tide gauge sites and that there is much to be learned about systematic errors from their inter-comparison.

270

271

\section{Acknowledgements}

272

273

We are grateful for discussions about the Pytharouli et al. paper with Peter Foden, Jeff Pugh 274 and other colleagues.

275

276

277

References

278

279

Intergovernmental Oceanographic Commission (IOC), Manual on Sea Level Measurement and Interpretation - An Update to 2006, IOC Manuals and Guides No. 14, vol. IV, 2006. Available online at: http://unesdoc.unesco.org/images/0014/001477/147773e.pdf 
Intergovernmental Oceanographic Commission (IOC), Global Sea Level Observing System 284 (GLOSS): Implementation Plan, IOC Technical Series, vol. 100, 2012. Available online at: 285 http://unesdoc.unesco.org/images/0021/002178/217832e.pdf

286

287 Intergovernmental Oceanographic Commission (IOC), Manual on Sea Level Measurement 288 and Interpretation - Radar Gauges, IOC Manuals and Guides No. 14, vol. V, 2016. Available online at: http://unesdoc.unesco.org/images/0024/002469/246981e.pdf

290

291

B. Martin Míguez, R. Le Roy, G. Wöppelmann, The use of radar tide gauges to measure 292 variations in sea level along the French coast, Journal of Coastal Research 24 (2008) 61-68, 293 doi:10.2112/06-0787.1

294

295

B. Martin Míguez, L. Testut, G. Wöppelmann, Performance of modern tide-gauges: towards 296 mm-level accuracy, Scientia Marina 76 (S1) (2012) 221-228, doi:10.3989/scimar.03618.18A

297

298

J. Park, R. Heitsenrether, W. Sweet, Water level and wave height estimates at NOAA tide 299 stations from acoustic and microwave sensors, Journal of Atmospheric and Oceanic 300 Technology, 31 (2014) 2294-2308, doi:10.1175/JTECH-D-14-00021.1.

301

302 D. Pugh, P. Woodworth, Sea-level science: Understanding tides, surges, tsunamis and mean 303 sea-level changes, Cambridge University Press, 2014. 
P.L. Woodworth, D.E. Smith, A one year comparison of radar and bubbler tide gauges at

https://journals.lib.unb.ca/index.php/ihr/article/view/20630/23792

308

P. L. Woodworth, A. Aman, T. Aarup, Sea level monitoring in Africa, African Journal of Marine Science 29 (2007), 321-330, doi:10.2989/AJMS.2007.29.3.2.332.

311

312 P. Woodworth, P. Foden, J. Pugh, A. Matthews, T. Aarup, A. Aman, E. Nkebi, J. Odamatey, R.

313 Facey, M.Y.A. Esmail, M. Ashraf, Insight into long term sea level change based on new tide 314 gauge installations at Takoradi, Aden and Karachi. International Hydrographic Review 1 315 (2009), 18-23. (https://journals.lib.unb.ca/index.php/ihr/article/download/20831/23991) 